
Not for reproduction, distribution or commercial use.

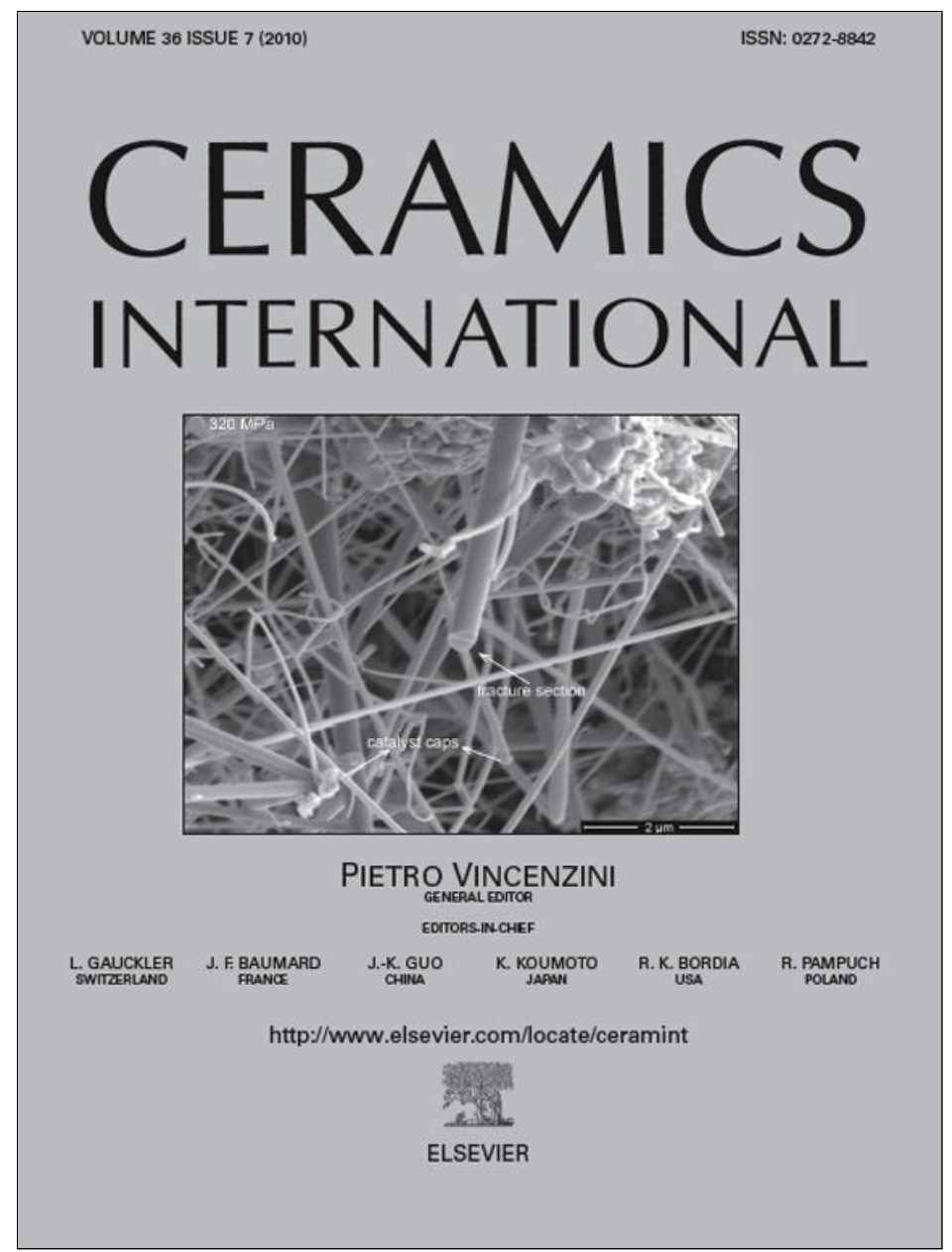

This article appeared in a journal published by Elsevier. The attached copy is furnished to the author for internal non-commercial research and education use, including for instruction at the authors institution and sharing with colleagues.

Other uses, including reproduction and distribution, or selling or licensing copies, or posting to personal, institutional or third party websites are prohibited.

In most cases authors are permitted to post their version of the article (e.g. in Word or Tex form) to their personal website or institutional repository. Authors requiring further information regarding Elsevier's archiving and manuscript policies are encouraged to visit:

http://www.elsevier.com/copyright 


\title{
Structure and properties of plasma sprayed $\mathrm{BaTiO}_{3}$ coatings
}

\author{
Pavel Ctibor ${ }^{\text {a,* }}$, Helene Ageorges ${ }^{b}$, Josef Sedlacek ${ }^{c}$, Radim Ctvrtlik ${ }^{d}$ \\ ${ }^{a}$ Institute of Plasma Physics, ASCR, Za Slovankou 3, 18200 Praha 8, Czech Republic \\ ${ }^{\mathrm{b}}$ CNRS - Laboratoire Sciences des Procedes Ceramiques et de Traitements de Surface (SPCTS), Universite de Limoges, 123 av. A. Thomas, \\ 87060 Limoges Cedex, France \\ ${ }^{\mathrm{c}}$ Department of Electrotechnology, Faculty of Electrical Engineering Czech Technical University, Technicka 2, 16627 Praha 6, Czech Republic \\ ${ }^{\mathrm{d}}$ Joint Laboratory of Optics, Institute of Physics of ASCR, 17. listopadu 50, 77207 Olomouc, Czech Republic \\ Received 11 March 2010; received in revised form 4 April 2010; accepted 5 May 2010 \\ Available online 18 June 2010
}

\begin{abstract}
Plasma spraying enables to create layers with thickness in a millimeter range adhering on various substrates. This paper provides a study of electric and mechanical properties of $\mathrm{BaTiO}_{3}$ coatings prepared by atmospheric plasma spraying. The spraying was carried out by a direct current gas-stabilized plasma gun. $\mathrm{BaTiO}_{3}$ was fed into the plasma jet as a feedstock powder prepared by a reactive sintering of micrometer-sized powders of $\mathrm{BaCO}_{3}$ and $\mathrm{TiO}_{2}$. Microstructure and phase composition are reported and discussed in connection with electric and mechanical properties. The ability of the used techniques to detect precisely the phase transformation temperatures of $\mathrm{BaTiO}_{3}$ plasma sprayed coatings is discussed as well. A depth-sensing indentation measurement was done between 290 and $520 \mathrm{~K}$ to provide local mechanical characterization. The elastic modulus has shown slightly higher values than that reported typically in papers focused on $\mathrm{BaTiO}_{3}$ ferroelectric thin films. The average Vickers microhardness is tested to characterize the samples in larger scale. A wear resistance in a slurry environment is reported as well. Dielectric properties are reported for the temperature window of existence of the tetragonal ferroelectric phase. Relative permittivity and loss factor are studied at frequency from $50 \mathrm{~Hz}$ to $1 \mathrm{MHz}$ and temperature from 260 to $400 \mathrm{~K}$.
\end{abstract}

(C) 2010 Elsevier Ltd and Techna Group S.r.l. All rights reserved.

Keywords: C. Electrical properties; C. Mechanical properties; E. Capacitors; $\mathrm{BaTiO}_{3}$; Plasma spraying

\section{Introduction}

Barium titanate, $\mathrm{BaTiO}_{3}$, is an interesting multifunctional oxide that exhibits complex phase appearance. Between $120{ }^{\circ} \mathrm{C}$ $(393 \mathrm{~K})$ and $1457{ }^{\circ} \mathrm{C}(1730 \mathrm{~K}) \mathrm{BaTiO}_{3}$ has a cubic perovskite structure that consists of corner linked oxygen octahedra containing $\mathrm{Ti}^{4+}$, with $\mathrm{Ba}^{2+}$. Cooling below $120{ }^{\circ} \mathrm{C}$ results in small displacements in the positions of the cations in the unit cell resulting in polar ferroelectric phase existing in the temperature interval between $5{ }^{\circ} \mathrm{C}(278 \mathrm{~K})$ and $120{ }^{\circ} \mathrm{C}$ [1].

The perovskite barium titanates $\mathrm{BaTiO}_{3}$ and $(\mathrm{Ba}, \mathrm{Sr}) \mathrm{TiO}_{3}$, due to high dielectric constant, are used frequently as multilayer capacitor components and sensors. However, it has been found that with respect to the electrical properties $\mathrm{BaTiO}_{3}$ in the form of thin-films does not reach the qualities of

\footnotetext{
* Corresponding author. Tel.: +42 266053727; fax: +42 286586389. E-mail address: ctibor@ipp.cas.cz (P. Ctibor).
}

bulk material. This difference was explained by a combination of the intrinsic dead layer effect, a stress effect, an effect of the microstructure within the thin film, and an effect of the stoichiometry [2]. In particular, the relative permittivity of films decreases when the film thickness is reduced [3]. The optimal dielectric characteristics are obtained for sintered $\mathrm{BaTiO}_{3}$ based sample with bulk density of about $5300 \mathrm{~kg} \mathrm{~m}^{-3}$ [4]. Any deviation from the stoichiometric $\mathrm{Ba} / \mathrm{Ti}$ ratio leads to suppression of the high relative permittivity of the ferroelectric barium titanate [5]. To detect the tetragonal $\mathrm{BaTiO}_{3}$ phase by X-ray diffraction, the split of peaks of $\left(\begin{array}{lll}0 & 0 & 2\end{array}\right)$ and $\left(\begin{array}{lll}2 & 0 & 0\end{array}\right)$ reflection is a well-established indication [6-8].

In general there are differences of the behavior of barium titanate in the form of a monocrystal, sintered bulk material and thin film [1,5]. Plasma spraying enables to create layers with 'bulk-like' thickness but adhering on a metallic substrate of various shapes. Free-standing parts of titanate ceramics can be fabricated as well by plasma spraying [9]. $\mathrm{BaTiO}_{3}$ itself was up to now very seldom plasma sprayed and the understanding of its 
behavior in the form of sprayed coating is not satisfactory. For coatings with the thickness of about $100 \mu \mathrm{m}$ the values of relative permittivity 50 and loss factor 0.08 were reported [10]. The dielectric properties of the plasma sprayed $\mathrm{BaTiO}_{3}$ were related to the degree of crystallinity [10]. The coatings containing more crystalline material have higher relative permittivity. The relative permittivity was affected also by cracks and splat interfaces within the coating [10]. The reported value of relative permittivity is however surprisingly low, because one and more orders higher values are typical for bulk $\mathrm{BaTiO}_{3}[11]$.

Concerning mechanical properties of plasma sprayed $\mathrm{BaTiO}_{3}$ even lower quantity of data is available. For a bulk material a stress-strain characteristic was shown to be markedly different for tetragonal and for cubic $\mathrm{BaTiO}_{3}$ phases [12]. Sintered $\mathrm{BaTiO}_{3}$ is reported to have microhardness of about 4.5 GPa and not markedly dependent upon load in frames of 0.25-2 $\mathrm{N}$ when tested by Knoop indentation [13].

The goal of our spraying experiments was to achieve thick enough coatings with high relative permittivity and sufficient mechanical quality. The focus of present paper is on selected aspects of the dielectric as well as structural and mechanical characteristics of the as-sprayed barium titanate coatings.

\section{Experimental}

\subsection{Material and specimen preparation}

$\mathrm{BaTiO}_{3}$ feedstock powder was obtained by crushing and sieving of sintered coarse agglomerates. Those agglomerates were prepared by a reactive sintering of micrometer-sized powders of $\mathrm{BaCO}_{3}$ and $\mathrm{TiO}_{2}$ used as starting materials. The sintering was carried out in Ceramic Capacitors Ltd., Hradec Kralove, Czech Republic. After sieving of the feedstock the size distribution was 20 and $63 \mu \mathrm{m}$ with an average at $40 \mu \mathrm{m}$, whereas the bulk density measured by helium pycnometry was $5722 \pm 1 \mathrm{~kg} \mathrm{~m}^{-3}$.

Gas-Stabilized Plasma gun (GPS) was used to perform Atmospheric Plasma Spraying (APS) of $\mathrm{BaTiO}_{3}$. The conventional d.c. GPS gun F4 consisted of a thoriated tungsten cathode of $10 \mathrm{~mm}$ in diameter with a conical tip and a copper anode/ nozzle of $7 \mathrm{~mm}$ in internal diameter (i.d.) and $28 \mathrm{~mm}$ in length. The plasma gas mixture used was argon/hydrogen with flow rates of 45/15 slm and in certain cases $53 / 7 \mathrm{slm}$. The powder was injected perpendicularly to the plasma jet axis with argon as a carrier gas (at constant flow rate $5 \mathrm{slm}$ at pressure $0.3 \mathrm{MPa}$ for all spray experiments) through a $1.8 \mathrm{~mm}$ i.d. injector located $3 \mathrm{~mm}$ downstream (called external injection) of the torch nozzle exit and $5 \mathrm{~mm}$ from the torch axis in radial direction. The system can process $1-5 \mathrm{~kg} \mathrm{~h}^{-1}$. Barium titanate was sprayed at arc power around $30 \mathrm{~kW}$ because the feedstock was coarser than reported in the work [14], describing an as-sprayed $\mathrm{BaTiO}_{3}$ microstructure as predominantly amorphous when the torch power was $37.8 \mathrm{~kW}$. The goal of using lower power at our experiments was to avoid or minimize such an overheating and associated amorphization. Spray distance was changed between 100 and $150 \mathrm{~mm}$ for various sets of samples. Plasma spraying deposition time was about five minutes to reach the thickness $0.9-1 \mathrm{~mm}$. The system included also two air cooling barriers to eliminate non-treated particles and maintain substrates and coatings under formation during spraying at the chosen temperature which was monitored by a IR pyrometer with 8-14 $\mu \mathrm{m}$ wavelength.

Substrates, rectangular shaped $(120 \mathrm{~mm} \times 20 \mathrm{~mm}) 3 \mathrm{~mm}$ thick, were made of carbon steel (Euronorm S355). Just before spraying, they were grit blasted with corundum with a mean diameter of $400 \mu \mathrm{m}$. The blasting pressure was $0.6 \mathrm{MPa}$ and the nozzle-substrate distance $100 \mathrm{~mm}$. The grit-blasting was made perpendicularly to the substrate. Then substrates were cleaned in the acetone in an ultrasonic bath. The resulting roughness was $R_{\mathrm{a}}=5.6 \pm 0.3 \mu \mathrm{m}$.

The substrates were disposed on a rotating sample holder which diameter was $90 \mathrm{~mm}$. This substrate holder was rotated (tangential speed of $1 \mathrm{~m} / \mathrm{s}$ ) with a horizontal axis and simultaneously translated back and forth orthogonally to the plasma jet axis at a velocity of $24 \mathrm{~mm} / \mathrm{s}$, with an excursion of $160 \mathrm{~mm}$, the plasma torch being stationary. The standoff distance was adjusted at the whished distance.

\subsection{Characterization techniques}

For microscopic observation and for microhardness measurements polished cross-sections as well as in-plane sections of coatings were prepared. The microstructure of plasma deposit was studied by Scanning Electron Microscopy (SEM). Energy Dispersive Spectroscopy (EDS) was used to analyze the chemical elements. Image analysis software was used to check several structural features such as porosity and content of "phases" with different color. The bulk density of powders was measured by pycnometry. The roughness was measured along a length of $48 \mathrm{~mm}$. The mean values of both selected parameters $\left(R_{\mathrm{a}}\right.$ and $\left.R_{\mathrm{z}}\right)$ were the averages of 20 random values. X-ray diffraction (XRD) was performed as phase identification with SIEMENS D5000 ${ }^{\mathrm{TM}}$ equipment allowed identifying phases present within powders and coatings. For estimation of the crystallinity of the plasma sprayed coating relative peak areas have been used. These have been calculated from relative ratios of the areas of the three main peaks ( 101,111 and 200$)$ from the tetragonal titanate phase.

Depth sensing indentation (DSI) was carried out with a calibrated diamond Berkovich indenter using NanoTest ${ }^{\text {TM }}$ NT600 instrument equipped with a computer-controled heating stage [15]. Heating was applied to both indenter and the sample. The nanoindentation tests were carried out at temperatures of $299,323,373,423$ and $523 \mathrm{~K}$. A square pattern with 36 (i.e. $6 \times 6$ ) indents was performed at each temperature, where the indentation load of $50 \mathrm{mN}$ was applied. The distance between neighbouring indents in the pattern was $50 \mu \mathrm{m}$. Loading and unloading rates were set to $2.5 \mathrm{mN} \mathrm{s}^{-1}$, dwell period was $5 \mathrm{~s}$. The data were adjusted by subtracting the indents whose loaddisplacement curve was of non-standard shape, namely, if subsequent visual control (by a stereomicroscope) verified a defect in the structure at the point of indentation. So, the results of this test should be seen as local elastic properties of the 
coating. The indentation hardness and modulus were determined from indentation curves according to the Oliver-Pharr method [16].

Conventional microhardness of the coatings was measured by optical microscope equipped with a Hanemann head and Vickers indenter using $1 \mathrm{~N}$ load applied over $15 \mathrm{~s}$ (IPP, Prague, Czech Rep.). The mean value of microhardness was calculated as an average from 20 indentations, which were aligned to create microhardness profiles from the coating surface to the substrate. Other microhardness tests were done at Limoges university, France, applying a $3 \mathrm{~N}$ load during $15 \mathrm{~s}$ and using a Vickers indenter.

Electric measurements were performed after removing the coatings from the metallic substrate. The surface of specimens was ground to eliminate surface roughness. Layers of aluminum as thin film electrodes were sputtered in a reduced pressure $\left(2 \times 10^{-3} \mathrm{~Pa}\right)$ on both sides of each sample. A threeelectrode measurement fixture was used to evaluate dielectric parameters of samples. Test fixture was inserted in a calibration cell of the Temperature Calibrator Isotech Venus 2140 apparatus working in temperature range from $-55^{\circ} \mathrm{C}$ to $140{ }^{\circ} \mathrm{C}$. The electric field was applied parallel to the spraying direction (i.e., perpendicular to the substrate surface). Capacity was measured in the frequency range from $50 \mathrm{~Hz}$ to $1 \mathrm{MHz}$ using a programmable impedance analyzer model PM6306 (Fluke, the Netherlands). Applied voltage was $1 \mathrm{~V}$ AC [9]. Relative permittivity $\varepsilon_{\mathrm{r}}$ was calculated from measured capacities $C_{\mathrm{P}}$ and specimen dimensions since $\varepsilon_{\mathrm{r}}$ is directly proportional to $C_{\mathrm{P}}$ by the Eq. (1).

$C_{\mathrm{P}}=\varepsilon_{0} \times \varepsilon_{\mathrm{r}} \times \frac{1}{k}$

where $\varepsilon_{0}=8.854 \times 10^{-12} \mathrm{~F} \mathrm{~m}^{-1} ; 1 / k[\mathrm{~m}]$ is defined as the ratio between the guarded surface and the thickness of the sample. This technique is accurate enough $\left(C_{\mathrm{P}} \pm 0.01 \mathrm{pF}\right)$ for dense materials $\left(d>95 \% d_{\mathrm{th}}\right)$ [17]. The measurement of the relative permittivity dependence on frequency was repeated at various temperatures from 260 to $400 \mathrm{~K}$, whereas near the precluded temperatures of phase transformations the interval was smaller then far from those temperatures. This same arrangement and equipment was used for the loss tangent measurement at the same frequencies and temperatures as capacity.

Slurry abrasion response of coatings (SAR test) was measured according to a modified ASTM G-75 test [18]. Main modification contains the fact that ASTM emphasizes the use of a reference sample, which is a bulk alloy - targeted to comparison with bulk metals and not with ceramic coatings. The authors of this paper are using successfully the SAR test without the ASTM reference samples [18]. The applied force was $22.2 \mathrm{~N}$ per specimen and alumina particles (two sizes of powders were used) mixed with water serving as the abrasive slurry. The test represents a $9216 \mathrm{~m}$ path divided into four increments with mass loss being measured at the end of each $2304 \mathrm{~m}$ increment, when the specimens were ultrasonically cleaned and weighed. The measurement was carried out in two slightly different alumina powders described precisely in [18]. Finally the results are expressed in cubic millimeters per meter of the distance passed in the slurry and Newton of the load. Accuracy of the measurement is approx. $\pm 8 \%$.

At the SAR test also a response of samples onto various abrasive medium particle sizes was tested. Two different sizes of alumina abrasive powder were used. The first series of tests was made in finer powder "P1" $(20-80 \mu \mathrm{m})$ and the second series in coarser powder "P2" (10-125 $\mu \mathrm{m})$. The second powder, however being of nominally smaller mean size, contains larger particles (over $100 \mu \mathrm{m}$ ), which are important for the wear action.

\section{Results and discussion}

Feedstocks for plasma spraying exhibited blocky morphology with facets as a result of cleavage at crushing - see Fig. 1a. Cross-sections of individual particles had shown that some of them are pore-free and crack-free whereas others include pores, see Fig. 1b. Fine cracks and dark straight lines were probably induced by applying a force at grinding. The dark straight lines have appearance like ferroelectric domains typical for sintered $\mathrm{BaTiO}_{3}[1,2,5,11]$. XRD pattern, Fig. 2, showed tetragonal phase of barium titanate feedstock powder.

The element composition of the powder measured by XRF was (in atomic \%): Ba 18-22; Ti 13-20; O 60-61. The variation was particle-to-particle, whereas the balance to $100 \%$ was in all cases carbon from the tape used for particle fixing. Some particles were slightly Ti-deficient.

Bulk density of the coating measured by pycnometry was $5365 \pm 2 \mathrm{~kg} \mathrm{~m}^{-3}$.

(a)

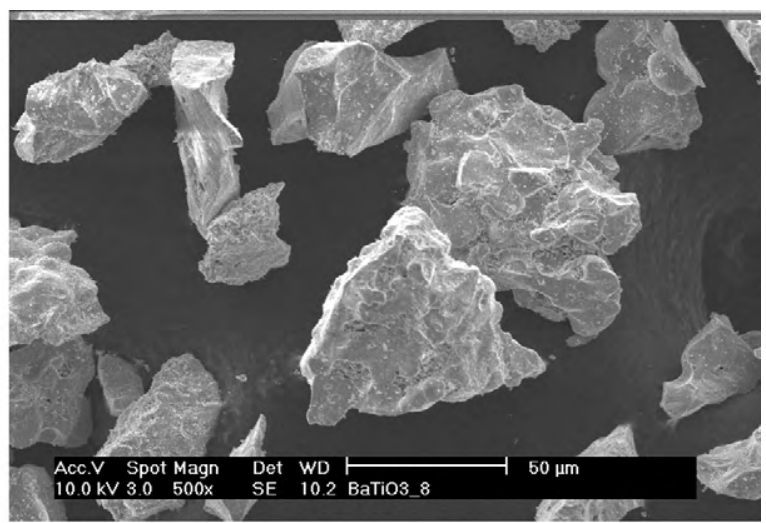

(b)

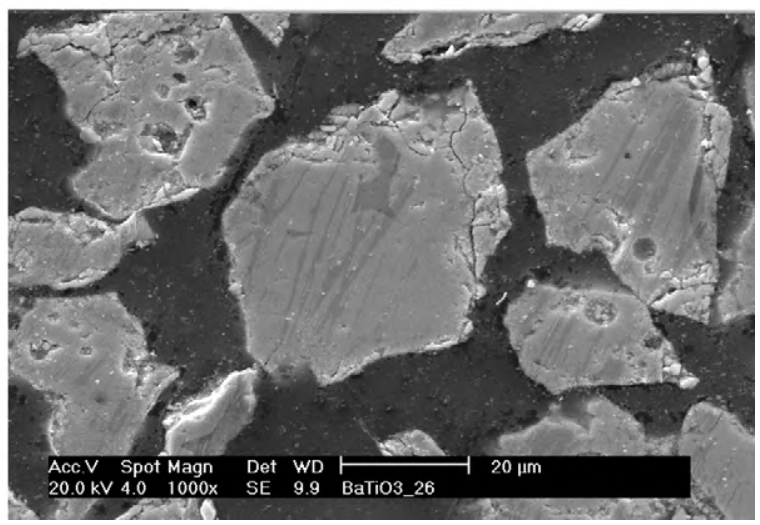

Fig. 1. SEM, SE images of $\mathrm{BaTiO}_{3}$ feedstock - (a) in surface view and (b) cross-section. 


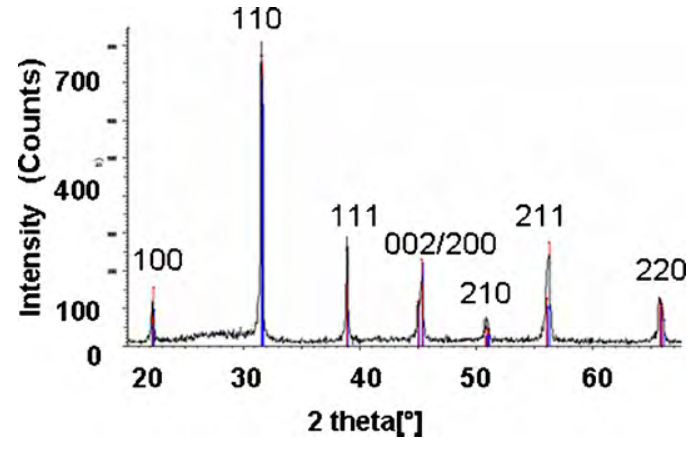

Fig. 2. XRD pattern of the barium titanate feedstock powder.

The chemical composition of the as-sprayed $\mathrm{BaTiO}_{3}$ coating is shown in Table 1. Carbon and gold are from the sputtered carbon layer and from gold tape used for discharging of this dielectric sample. The content of Ba versus $\mathrm{Ti}$ is stoichiometric (within the precision of the used technique) whereas oxygen content is apparently sub-stoichiometric. However XRD pattern, Fig. 3, corresponds strictly to the tetragonal phase, which was confirmed to be the constituent of feedstock powder as well as of coatings. In the coating there is certain quantity of amorphous phase, manifested itself by a halo centered around $29^{\circ}$ in the pattern and estimated as 20\% (using peak deconvolution function of the software Topas (Bruker)). In the other hand the dark color of the coating surfaces indicates certain oxygen deficiency. Intensity ratio of individual peaks of the feedstock as well as of the coating is very similar to patterns reported in the literature [6].

Fig. 4 brings the microstructure of a materialographically prepared cross-section. Fig. 4a shows quit dense structure with few cracks and predominantly rounded fine pores. Fig. 4b shows the section after etching in $\mathrm{HNO}_{3}$ for $2 \mathrm{~min}$. The networks of cracks are here more easily observable whereas also the finer pores can be easily seen. Moreover certain variance in grayscale appeared that corresponds to shapes of individual splats. Such a feature is mentioned in [14] with explanation that "composition difference" is responsible for it. According to the results, it is most probably associated with a subtle change in tetragonality (crystal cell parameter $c$ changes with increasing oxygen deficiency [19]) of the $\mathrm{BaTiO}_{3}$ lattice or also with amorphous fraction.

Fig. 5 brings the light micrographs of a materialographically polished samples. On the Fig. 5a we can see individual splats in a cross-section. The structure is rather dense; few vertical cracks are artifacts from section preparation. Fig. 5b shows the

Table 1

XRF results of the coating sprayed using SD $120 \mathrm{~mm}$.

\begin{tabular}{lcc}
\hline Element & Weight [\%] & Atomic [\%] \\
\hline $\mathrm{C}$ & 3.36 & 12.67 \\
$\mathrm{O}$ & 17.19 & 48.69 \\
$\mathrm{Ti}$ & 20.41 & 19.31 \\
$\mathrm{Ba}$ & 57.47 & 18.97 \\
$\mathrm{Au}$ & 1.57 & 0.36 \\
Total & 100 & 100 \\
\hline
\end{tabular}

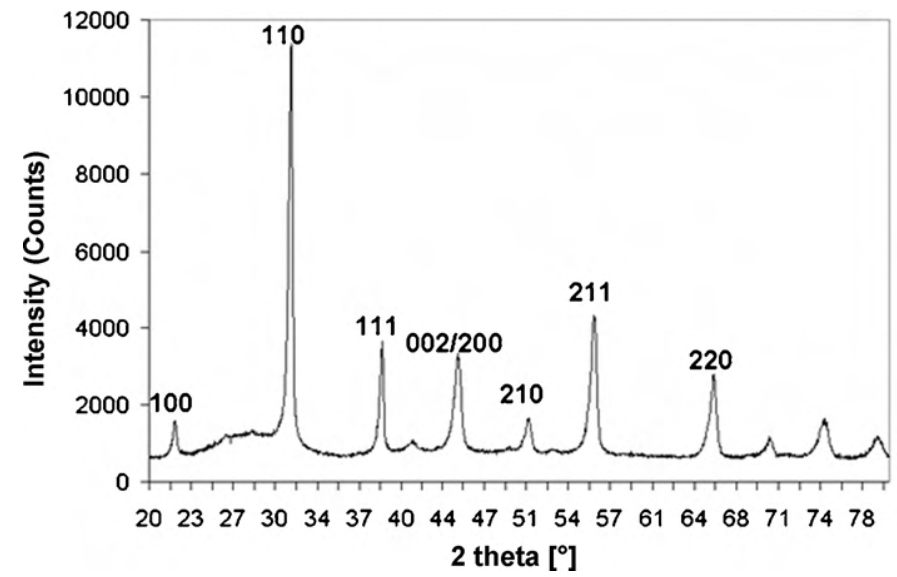

Fig. 3. XRD pattern of the barium titanate coating.

in-plane direction section, i.e. spray direction. Certain variation in grayscale corresponds to shapes and sizes of individual splats and is in light microscope visible without any etching. The ratio of this darker "phase" was measured by image analysis as $16.3 \%$. Other characteristics of porosity are summarized in the Table 2.

Surface roughness of as-sprayed coating is listed in the Table 3 together with the values after wear test. The wear test acts like grinding and therefore both parameters characterizing roughness decreased after SAR test. The measurement was done along the path of the movement at SAR test. The relatively

(a)

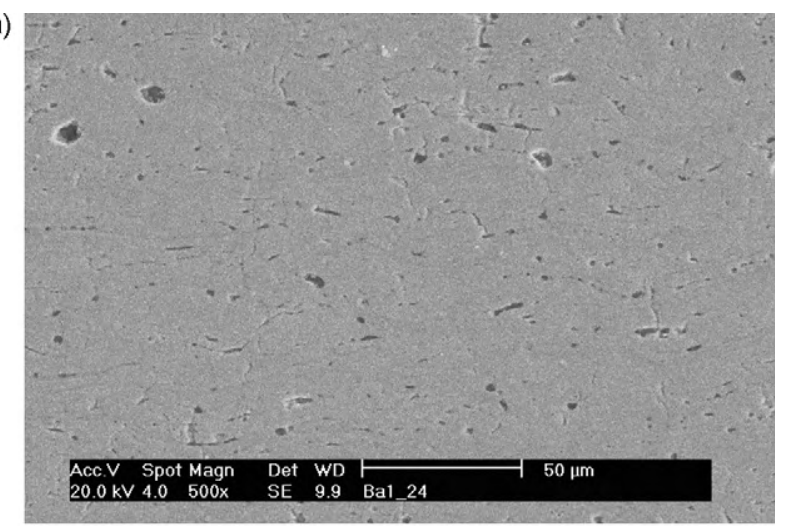

(b)

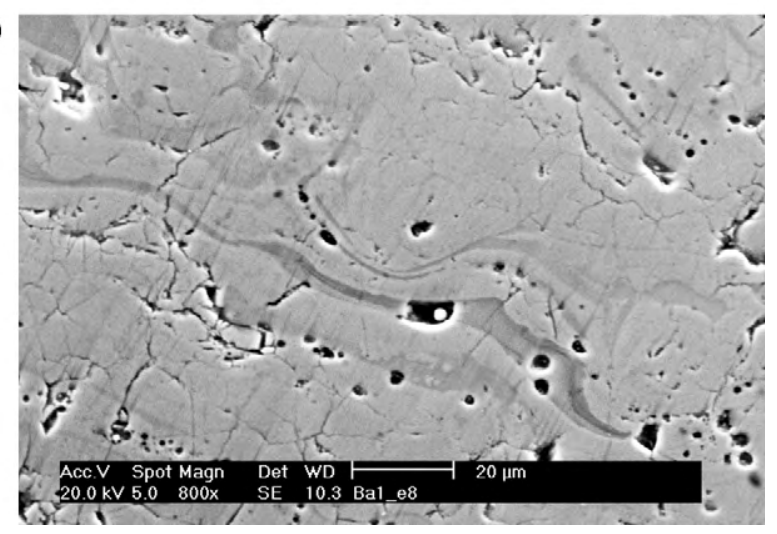

Fig. 4. SEM-SE cross-section of $\mathrm{BaTiO}_{3}$ coating: (a) polished and (b) etched after polishing. 
(a)

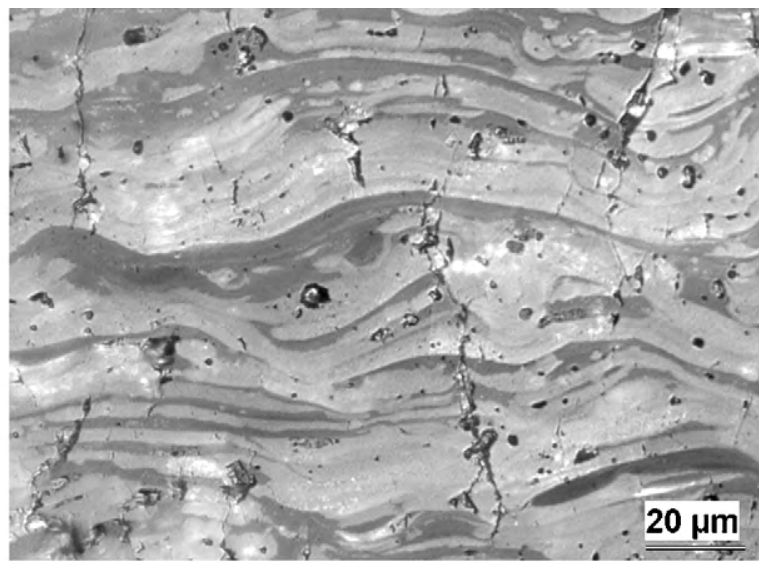

(b)

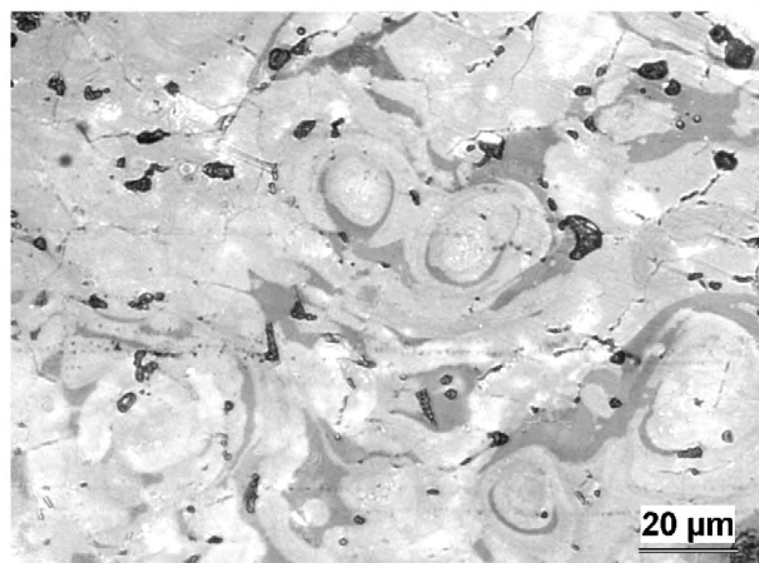

Fig. 5. Light microscopy views of polished $\mathrm{BaTiO}_{3}$ coating: (a) cross-section and (b) in-plane direction.

high standard deviations after SAR reflect the fact that both, smooth and coarse, areas are present. This is an indication of a limited wear resistance.

Slurry abrasion response results are present in Table 4 with other plasma spayed materials results in order to make some comparison. Powder P1 led to higher wear coefficient representing lower wear resistance. Other ceramic plasma sprayed coatings were tested at the same conditions. Chromium oxide represents ultra-hard and also well wear resistant material whereas titanium oxide has a medium wear resistance. Barium titanate belongs also to this group of ceramic materials.

Fig. 6 presents a typical load-depth curve of $\mathrm{BaTiO}_{3}$ coating on cross-section at room temperature. The loading branch starts from zero whereas after unloading a residual indent with depth around $300 \mathrm{~nm}$ stays present. Such curves, i.e. without any jumps and sharp changes of the slope on both branches, were included in the evaluation of elastic modulus and microhardness. Resulting indentation effective modulus $(E)$ is $148 \pm 22 \mathrm{GPa}$ whereas values of about $125 \mathrm{GPa}$ are reported in engineering databases (Matweb.com) and as low as $67 \mathrm{GPa}$
Table 3

Surface roughness results $[\mu \mathrm{m}]$.

\begin{tabular}{lllll}
\hline Sample & $\begin{array}{l}\text { As-sprayed, } \\
\mathrm{Ra}\end{array}$ & $\begin{array}{l}\text { As-sprayed, } \\
\mathrm{Rz}\end{array}$ & $\begin{array}{l}\text { After SAR, } \\
\mathrm{Ra}\end{array}$ & $\begin{array}{l}\text { As-sprayed, } \\
\mathrm{Rz}\end{array}$ \\
\hline Mean value & $8.7 \pm 0.9$ & $59.0 \pm 7.9$ & $2.4 \pm 0.9$ & $16.8 \pm 5.6$ \\
\hline
\end{tabular}

Table 4

SAR results - wear coefficient $\left[\mathrm{mm}^{3} / \mathrm{Nm}\right]$.

\begin{tabular}{lll}
\hline Sample & SAR powder P1 & SAR powder P2 \\
\hline $\mathrm{BaTiO}_{3}$ & 0.00116 & 0.00092 \\
Plasma sprayed $\mathrm{Cr}_{2} \mathrm{O}_{3}$ & 0.00030 & - \\
Plasma sprayed $\mathrm{TiO}_{2}$ & 0.00101 & - \\
\hline
\end{tabular}
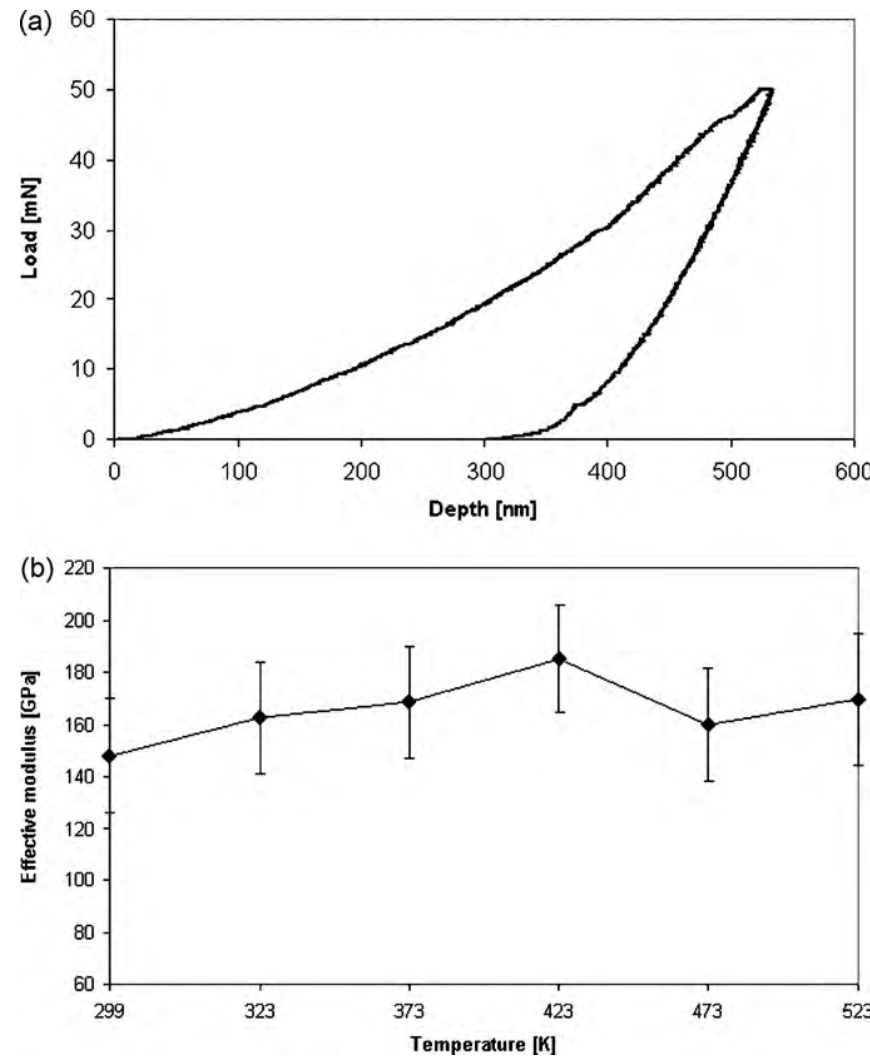

Fig. 6. (a) Example of a typical load - depth recording of a DSI measurement at room temperature and (b) dependence of elastic modulus on temperature.

in a research paper focused on thin ferroelectric films [20]. Corresponding average hardness is $8.1 \pm 1.5 \mathrm{GPa}$. The temperature evolution of elastic modulus is displayed in Fig. 6.b. The highest $E$ value $185 \mathrm{GPa}$ is at $150{ }^{\circ} \mathrm{C}(423 \mathrm{~K})$. According to the measurements it is possible to deduce than above the tetragonal to cubic $(\mathrm{t}-\mathrm{c})$ phase transformation

Table 2

Image analysis results.

\begin{tabular}{lllll}
\hline Parameter & Porosity $[\%]$ & Mean pore size $[\mu \mathrm{m}]$ & Max. pore size $[\mu \mathrm{m}]$ & Pores per mm $^{2}$ \\
\hline Value & $4.7 \pm 0.5$ & 4.5 & 11.4 & 5840 \\
\hline
\end{tabular}




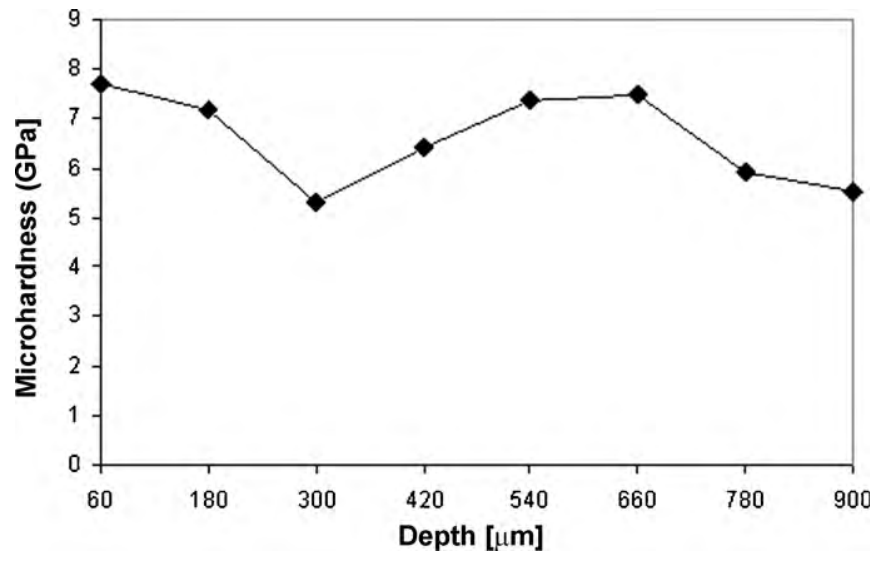

Fig. 7. Microhardness in dependence on depth from the coating surface.

temperature the modulus $E$ is slightly higher. This fact agrees with the literature [21].

Mean conventional Vickers microhardness at $1 \mathrm{~N}$ load is $6.6 \pm 1.2 \mathrm{GPa}$. This value is lower than hardness obtained at DSI. This is expectable because of 20 times lower load at DSI. A certain decrease of the microhardness in the depth approximately $300 \mu \mathrm{m}$ from the coating surface is observed in Fig. 7, which is most probably caused by an irregularity in powder feeding resulting in weaker inter-splat cohesion within certain depth. Vickers microhardness at $3 \mathrm{~N}$ load brings even lower hardness values $5.3 \pm 0.2 \mathrm{GPa}$. The hardness is strongly load-dependent because of defects in coatings like microcracks and pores.

Fig. 8 brings relative permittivity $\varepsilon_{\mathrm{r}}$ measurement results. Dependence of permittivity on frequency exhibits progressive decrease. This trend is usual [22] whereas slope of the decrease with growing frequency is in the case of our plasma sprayed $\mathrm{BaTiO}_{3}$ coatings higher compared to bulk. This fact can be associated with the presence of pores, cracks and predominantly also imperfections near the boundary with the substrate (c.f. the hardness drop in Fig. 7). The dependence of permittivity on temperature exhibits a maximum at $394 \mathrm{~K}$, which was the highest measured temperature. This temperature is only $1 \mathrm{~K}$ above the theoretical temperature of the $\mathrm{t}-\mathrm{c}$ phase transformation. At all frequencies there is monotonous increase of the permittivity with temperature. The permittivity values at as low frequencies as 50 or $100 \mathrm{~Hz}$ and temperatures above $370 \mathrm{~K}$ exhibit a pronounced growth. We assume it as a result of ferroelectric transition.

However at frequencies between $1 \mathrm{kHz}$ and $1 \mathrm{MHz}$ is absence of a sharp maximum of permittivity near the $t-c$ transformation temperature. Concerning the second transformation, theoretically at $278 \mathrm{~K}$, there is not sharp change of permittivity at any studied frequency. We consider that the amorphous fraction as well as microstructural imperfections along the splat boundaries are responsible for such a weak response of permittivity to the temperature changes.

Loss tangent was about 0.3 for $1 \mathrm{kHz}$ at room temperature and decreases with frequency and also with temperature. This

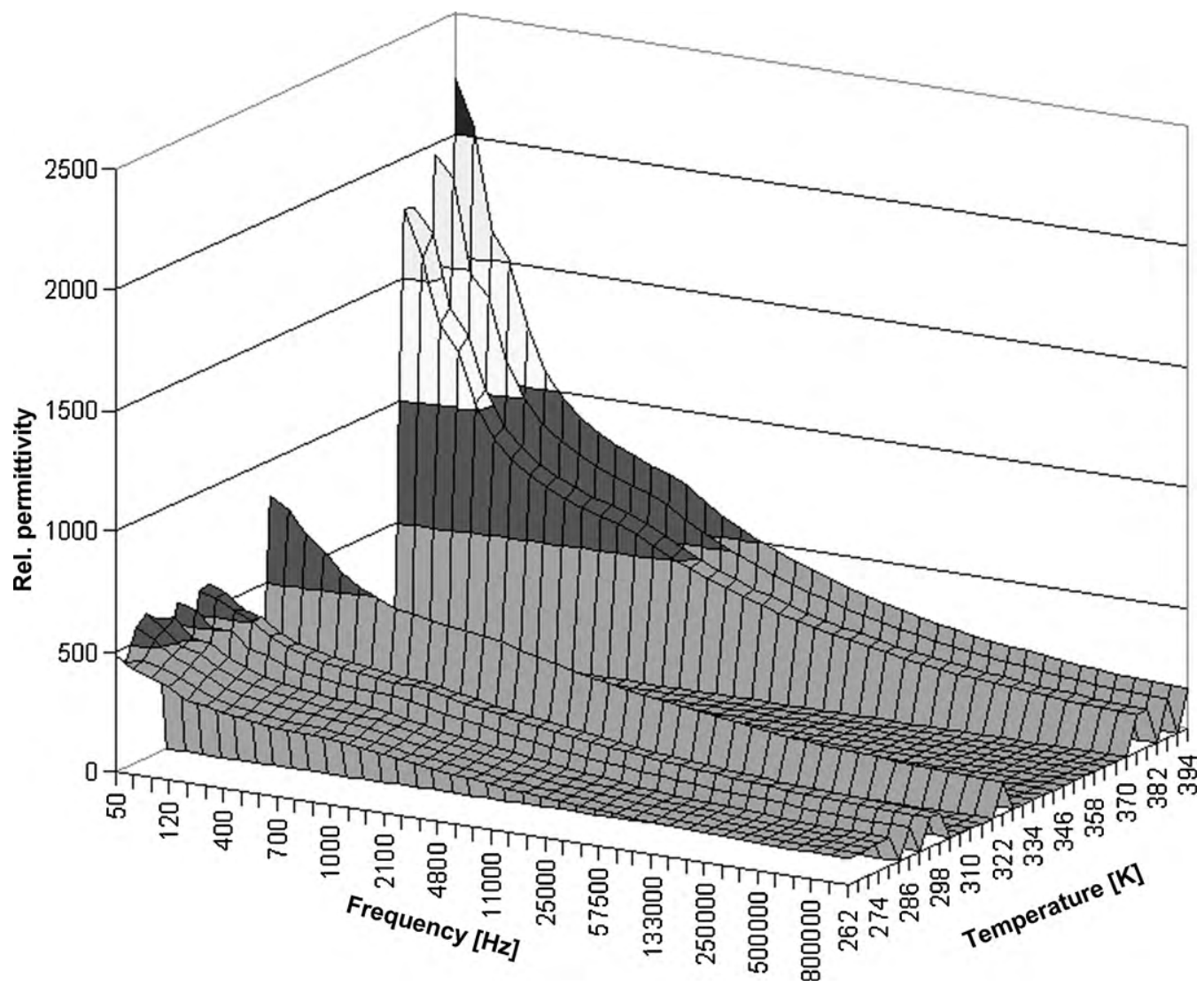

Fig. 8. Dependence of permittivity on frequency and temperature. 
value is high. Here the influence of the structural disorder associated with Ba vs. Ti ratio imbalance seems to be crucial.

Various papers deal with an effect of hydrogen-rich atmosphere onto $\mathrm{BaTiO}_{3}$ during its synthesis or subsequent annealing. An interstitial $\mathrm{H}$ atom was found to bind to one of the $\mathrm{O}$ atoms of $\mathrm{BaTiO}_{3}$ structure forming the $\mathrm{OH}$ group [23]. Such a defect in the $\mathrm{BaTiO}_{3}$ structure contributes to a decrease of resistivity as well as marked rise of the loss tangent because the material starts to behave like n-type semiconductor [24]. This is because in such defective cells $\mathrm{Ti}^{4+}$ is reduced to $\mathrm{Ti}^{3+}$ [25]. Hydrogen incorporation in barium titanate films during the deposition process can contribute to the transport phenomena by introducing several features. At temperature higher than $-30{ }^{\circ} \mathrm{C}$ protons (from hydrogen) contribute to the conduction mechanism as mobile ionic species [24]. In addition, protons have been proposed to induce n-type conductivity by generating shallow donor levels within the bandgap in titanates [24]. We suggest that reaction of $\mathrm{BaTiO}_{3}$ with hydrogen ions in plasma can follow the principles expressed in [26]:

$$
\mathrm{BaTiO}_{3}+2 \mathrm{H}^{+}=\mathrm{Ba}^{2+}+\mathrm{TiO}_{2}(\text { rutile })+\mathrm{H}_{2} \mathrm{O}
$$

Concerning the tetragonal to cubic $(\mathrm{t}-\mathrm{c})$ phase transition and its influence on relative permittivity $\varepsilon_{\mathrm{r}}$, it is possible to find in the literature very contradictory statements. Sometimes the tetragonal phase is reported to have $\varepsilon_{\mathrm{r}}$ higher than the cubic phase $[27,28]$, in other works $[29,30]$ is the opposite opinion expressed and demonstrated. Also the well known fact that the maximum of $\varepsilon_{\mathrm{r}}$ lies at the transformation temperature [11,31] is reported with a variety of modifications. Several works had shown this maximum as very sharp [11,30], elsewhere is it presented as rather flat [27].

The values of $\varepsilon_{\mathrm{r}}$ are connected with the grain size [2,31] of $\mathrm{BaTiO}_{3}$, which is at bulk fabrication processes associated with the size of the initial powders. For the grain sizes comparable with the splat thickness at plasma spraying (e.g. $2-5 \mu \mathrm{m}$ ) the most frequently reported values of $\varepsilon_{\mathrm{r}}$ are about 1000-1500 [11,30-33]. The frequency for which this $\varepsilon_{\mathrm{r}}$ was obtained is seldom indicated [30] in the literature. In the mentioned study [30], $\varepsilon_{\mathrm{r}}$ approximately is 1000 at $1 \mathrm{kHz}$.

Practically the same what was written above about $\mathrm{t}-\mathrm{c}$ phase transition versus relative permittivity can be said also about mechanical properties as elastic modulus and local hardness. At the transition temperature $T_{\mathrm{c}}$ a local minimum of elastic modulus was described [21]. Modulus of cubic phase is typically reported as higher than that of tetragonal phase [21]. But the ratio of moduli of these two phases varies in dependence on sample manufacturing and measurement conditions [12]. From the results reported here the exact $t-c$ transformation temperature cannot be proved clearly. This temperature varies with grain size, presence of impurities, etc.

\section{Conclusions}

The goal of this study was to elaborate $\mathrm{BaTiO}_{3}$ coating by plasma spraying and study its properties. We have achieved nearly $1 \mathrm{~mm}$ thick coatings with relative permittivity much higher than thermally sprayed coatings reported in literature. However the dielectric properties of typical bulk $\mathrm{BaTiO}_{3}$ ceramics are even better. The investigation of the main factors responsible for this discrepancy is still in progress and here only the part of it was presented. Among major factors responsible for the worse dielectric characteristics than typical ones for bulk we must include: (i) not fully crystalline structure of our plasma coatings, (ii) lamellar microstructure witch defects like fine pores and cracks and (iii) certain variability in elemental composition within the entire sample volume associated with extraordinary sensitivity of the material on the atmosphere during the spraying. In the other hand our coatings have good mechanical quality, which is comparable with e.g. plasma sprayed $\mathrm{TiO}_{2}$. This fact in combination with specific features of plasma spray technology can offer promising solutions for the industry - e.g. high area embedded thermistors or parts with electric field-sensitive surfaces.

\section{Acknowledgment}

The work done at Institute of Plasma Physics was supported by the Academy of Science of the Czech Republic under project AV0 Z 20430508. The work done at and Institute of Physics was supported by the Academy of Science of the Czech Republic under project KAN301370701.

\section{References}

[1] M.H. Zhao, D.A. Bonnell, J.M. Vohs, Effect of ferroelectric polarization on the adsorption and reaction of ethanol on $\mathrm{BaTiO}_{3}$, Surface Science 602 (2008) 2849-2855

[2] N. Setter, R. Waser, Electroceramic materials, Acta Materialia 48 (2000) 151-178.

[3] H.Z. Jin, J. Zhu, P. Ehrhart, F. Fitsilis, C.L. Jia, S. Regnery, K. Urban, R. Waser, An interfacial defect layer observed at $(\mathrm{Ba}, \mathrm{Sr}) \mathrm{TiO}_{3}-\mathrm{Pt}$ interface, Thin Solid Films 429 (2003) 282-285.

[4] V.V. Mitic, I. Mitrovic, The influence of $\mathrm{Nb}_{2} \mathrm{O}_{5}$ on $\mathrm{BaTiO}_{3}$ ceramics dielectric properties, Journal of the European Ceramic Society 21 (2001) 2693-2696.

[5] R. Waser, Modeling of electroceramics - applications and prospects, Journal of the European Ceramic Society 19 (1999) 655-664.

[6] P. Yu, B. Cui, Z. Chany, Preparation and characterization of Ag-doped $\mathrm{BaTiO}_{3}$ based X7R ceramics, Materials Research Bulletin 44 (2009) 893-897.

[7] L. Simon-Seveyrat, A. Hajjaji, Y. Emziane, B. Guiffard, D. Guyomar, Reinvestigation of synthesis of $\mathrm{BaTiO}_{3}$ by conventional solid-state reaction and oxalate coprecipitation route for piezoelectric applications, Ceramics International 33 (2007) 35-40.

[8] L. Wu, M.Ch. Chure, K.K. Wu, W.Ch. Chang, M.J. Yang, W.K. Liu, M.J. $\mathrm{Wu}$, Dielectric properties of barium titanate ceramics with different materials powder size, Ceramics International 35 (2009) 957-960.

[9] P. Ctibor, J. Sedlacek, K. Neufuss, P. Chraska, Dielectric relaxation in calcium titanate-containing ceramics prepared by plasma spraying, Ceramics International 29 (2003) 955-960.

[10] A.H. Dent, A. Patel, J. Gutleber, E. Tormey, S. Sampath, H. Herman, High velocity oxy-fuel and plasma deposition of $\mathrm{BaTiO}_{3}$ and $(\mathrm{Ba}, \mathrm{Sr}) \mathrm{TiO}_{3}$, Materials Science and Engineering B 87 (2001) 23-30.

[11] R.C. Buchanan, Ceramic materials foe electronics, 3rd edition, M. Dekker, New York, USA, 2004.

[12] T.A. Asare, Investigating Ferroelastic and Piezoelectric Vibration Damping Behavior in Nickel-Barium Titanate and Nickel-PZT Composites, 
Diss. FVPI, Faculty of the Virginia Polytechnic Institute, Blacksburg, Virginia, 2007.

[13] E. Park, J.R. Routbort, Z. Li, Anisotropic microhardness in single-crystal and polycrystalline $\mathrm{BaTiO}_{3}$, Journal of Materials Science 33 (1998) 669673.

[14] Y.M. Kim, K.H. Baik, K.S. Park, Microstructure evolution and dielectric properties of plasma sprayed $\mathrm{BaTiO}_{3}$ coatings, in: B.R. Marple, M.M Hyland, Y.C. Lau, C.J. Li, R.S. Lima, G. Montavon (Eds.), Proceedings of Int. Thermal Spray Conf, 2009, pp. 547-550.

[15] R. Ctvrtlik, M. Stranyanek, P. Bohac, L. Jastrabik, NanoTest ${ }^{\mathrm{TM}}$ NT600 - a device for analyses of mechanical properties of materials, Materials Structure 13 (2) (2006) 90-93.

[16] W.C. Oliver, G.M. Pharr, Improved technique for determining hardness and elastic modulus using load and displacement sensing indentation experiments, Journal of Materials Research 7 (6) (1992) 1564-1580.

[17] O. Morey, P. Goeuriot, D. Juve, D. Treheux, Dielectric investigations on 'MgAlON' compounds: role of nitrogen content, Journal of the European Ceramic Society 23 (2) (2003) 345-355.

[18] P. Ctibor, M. Kasparova, J. Bellin, E. Le Guen, Plasma spraying and characterization of tungsten carbide-cobalt coatings by the water-stabi-

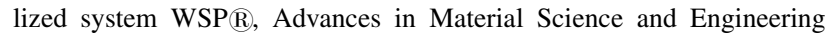
(2010) 1-11, Article ID 254848.

[19] H.Z. Guo, Z.H. Chen, B.L. Cheby, H.B. Lu, L.F. Liu, Y.L. Zhou, Structure dynamics of strongly reduced epitaxial $\mathrm{BaTiO}_{3-x}$ studied by Raman scattering, Journal of the European Ceramic Society 25 (2005) 2347-2352.

[20] L. Wucherer, J.C. Nino, G. Subhash, Mechanical properties of $\mathrm{BaTiO}_{3}$ open-porosity flaks, Journal of the European Ceramic Society 29 (2009) 1987-1993.

[21] B.L. Cheby, M. Gabbay, Duffy W.Jr., G. Fantozzi, Mechanical loss and Young's modulus associated with phase transitions in barium titanate based ceramics, Journal of Materials Science 31 (1996) 4951-4955.

[22] X. Wang, L. Zhang, H. Liu, J. Zhai, X. Yao, Dielectric nonlinear properties of $\mathrm{BaTiO}_{3}-\mathrm{CaTiO}_{3}-\mathrm{SrTiO}_{3}$ ceramics near the solubility limit, Materials Chemistry and Physics 112 (2008) 675-678.
[23] J. Chimborazo, M. Castillo, C. Velasco, A. Stashans, $\mathrm{H}$ atom in $\mathrm{BaTiO}_{3}$ and $\mathrm{CaTiO}_{3}$ crystals: structure, electronic properties, and diffusion, Proceedings of SPIE Advanced Organic and Inorganic Optical Materials 5122 (2003) 280

[24] F. El Kamel, P. Bonin, Proton related defects in $\alpha-\mathrm{BaTiO}_{3}: \mathrm{H}$ films based MIM capacitors, Solid State Ionics 180 (2009) 853-856.

[25] D.C. Sinclair, J.M.S. Skakle, F.D. Morrison, R.I. Smith, T.P. Beales, Structure and electrical properties of oxygen-deficient hexagonal $\mathrm{BaTiO}_{3}$, Journal of Material Chemistry 9 (6) (1999) 1327-1331.

[26] S. Lee, U. Paik, V.A. Hackley, Y.G. Jung, K.J. Yoon, Microstructure and permittivity of sintered $\mathrm{BaTiO}_{3}$ : influence of particle surface chemistry in an aqueous medium, Materials Research Bulletin 39 (2004) 93-102.

[27] J.G. Hyun, S. Lee, S.D. Cho, K.W. Paik, Frequency and temperature dependence of dielectric constant of Epoxy/ $/ \mathrm{BaTiO}_{3}$ composite embedded capacitor films (ECFs) for organic substrate, Proceedings of Electronic Components and Technology Conference (2005).

[28] M. Valant, A. Dakskobler, M. Ambrozic, T. Kosmac, Giant permittivity phenomena in layered $\mathrm{BaTiO}_{3}-\mathrm{Ni}$ composites, Journal of the European Ceramic Society 26 (2006) 891-896.

[29] M.L. Napijalo, Z. Nikolic, J. Dojcilovic, M.M. Napijalo, L. Novakovic, Temperature dependence of electric permittivity of linear dielectrics with ionic and polar covalent bonds, Journal of Physics and Chemistry of Solids 59 (8) (1998) 1255-1258.

[30] G. Zhan, A.K. Mukerjee, J.D. Kuntz, J. Wan, High density barium titanate of high permittivity, U.S. Patent No. 6,905,649 B2, 2005.

[31] R.L. Brutchey, G. Cheng, Q. Gu, D.E. Morse, Positive temperature coefficient of resistivity in donor-doped $\mathrm{BaTiO}_{3}$ ceramics derived from nanocrystals synthesized at low temperature, Advanced Materials 20 (2008) 1029-1033.

[32] T. Hiramatsu, T. Tamura, N. Wada, H. Tamura, Y. Sakabe, Effects of grain boundary on dielectric properties in fine-grained $\mathrm{BaTiO}_{3}$ ceramics, Materials Science and Engineering B 120 (2005) 55-58.

[33] W.H. Tuan, S.K. Lin, The microstructure-mechanical properties relationships of $\mathrm{BaTiO}_{3}$, Ceramics International 25 (1999) 35-40. 